\title{
COMUNICAÇÃO
}

\section{ANGIOSTRONGILÍASE ABDOMINAL. PRIMEIRO RELATO DE CASO AUTOOCTONE DE MINAS GERAIS}

\author{
Ademir Rocha, José Moscardini Sobrinho e Eliana Chaves Salomão
}

A angiostrongilíase abdominal é causada pelo Angiostrongylus costaricensis Morera \& Céspedes, 1971, um parasita habitual de ramos arteriais mesentéricos de ratos, tendo lesmas como hospedeiros intermediários; acidentalmente, este nematelminto pode localizar-se em ramos das artérias mesentéricas do homem, podendo causar arterite, trombose, edema e infarto dos intestinos, enterite e/ou colite, suboclusão intestinal e peritonite ${ }^{13910}$. Em geral, o processo manifesta-se, clinicamente, como abdome agudo ou massa abdominal; o hemograma evidencia, na maioria dos casos, leucocitose com marcante eosinofilia 4 .

A doença tem sido observada em diversos países das Américas, desde os Estados Unidos até a Argentina ${ }^{9}$. No Brasil, vem sendo detectada especialmente nos Estados da Região Sul (com destaque para o Rio Grande do Sul) e de São Paulo ${ }^{3}$. Dois casos foram relatados no Distrito Federal ${ }^{25}$. O casos cuja descrição se segue representa, a julgar pela literatura, o primeiro autóctone de Minas Gerais.

O paciente era um menino de nove anos, branco, natural e procedente de Uberlândia(MG), que chegou ao Hospital com queixa de dor abdominal moderada, com exacerbação há um dia. A dor, de início, era difusa, localizando-se, posteriormente, na fossa ilíaca direita; acompanhava-se de náuseas, vômitos e distensão abdominal. A criança mostrava regular estado geral, palidez cutâneo-mucosa e temperatura axilar de $37,6^{\circ} \mathrm{C}$. O abdome era globoso, doloroso à palpação, e apresentava massa dura e fixa da fossa ilíaca direita, com cerca de $10 \mathrm{~cm}$ de maior diâmetro. No hemograma, notaram-se, como dados mais relevantes, leucocitose $\left(13.500 \mathrm{~mm}^{3}\right)$

Departamento de Patologia do Centro de Ciências Biomédicas, Universidade Federal de Uberlândia e Casa de Saúde "Santa Marta", Uberlândia, MG.

Recebido para publicação em 08/07/91. com neutrofilia ( $58 \%$ de segmentos e $2 \%$ de bastonetes) e eosinofilia (20\%).

Com a hipótese diagnóstica de apendicite aguda, o paciente foi submetido à laparotomia exploradora, na qual se encontrou tumoração dura de limites imprecisos, localizada em ceco e início do colo ascendente; o íleo e o jejuno estavam distendidos, e havia discreta ascite sero-hemorrágica e múltiplos linfonodos discreta ou moderadamente infartados no mesocolo e mesentério; o apêndice não parecia inflamado. Realizou-se a ressecção do colo direito, ceco e segmento de íleo terminal, seguida de anastomose látero-lateral do íleo com o colo transverso.

O exame anatomopatológico da peça cirúrgica revelou parede intestinal moderadamente espessada, firme e brancacenta, com áreas de hemorragia recente e semi-oclusão do lume, de modo especial ao nível do ceco (Figura 1). Havia áreas de ulceração superficial da mucosa e de hemorragia recente na serosa. Dezoito linfonodos foram dissecados nos mesos. Microscopicamente, observaram-se, na parede cecal: infiltração leucocitária maciça de todas as camadas, com predomínio acentuado de granulócitos eosinófilos; arterite e arteriolite eosinofílicas; trombos arteriais ocludentes e semiocludentes; granulomas de corpo estranho, em distribuição esparsa, na submucosa, muscular e serosa, em parte relacionados a ovos de parede delgada (Figura 2); vermes no lume de arteríolas da submucosa, cortados de forma transversal ou oblíqua (Figura 3); focos de necrose coagulativa e hemorragia recente. Nos cortes de íleo, apêndice e colo ascendente, constatou-se quadro inflamatório inespecífico, com menor exsudato de eosinófilos, sem helmintos ou granulomas. Os linfonodos exibiam pequenos focos de necrose e intensa infiltração eosinofílica dos seios, cordões e zona paracortical. O diagnóstico anatomopatológico, diante dos achados ora descritos, foi de angiostrongiliíase abdominal. 
Comunicação. Rocha A, Moscardini Sobrinho J, Salomão EC. Angiostrongilíase abdominal. Primeiro relato de caso autóctone de Minas Gerias. Revista da Sociedade Brasileira de Medicina Tropical 24:266-267, out-dez, 1991

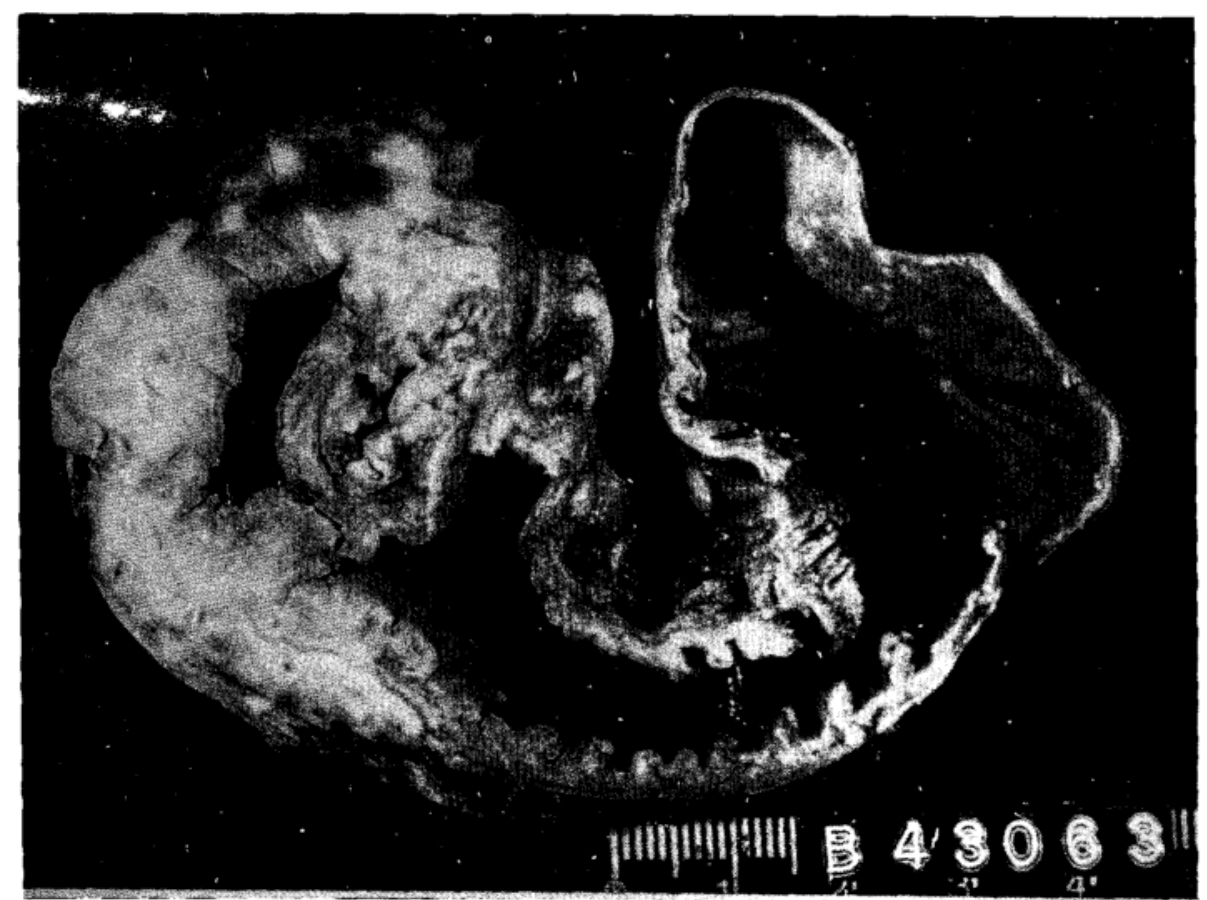

Figura 1 - Corre longitudinal de segmento intestinal, mostrando: espessamento da parede, especialmente do ceco; áreas de hemorragia recente; suboclusão do lume.

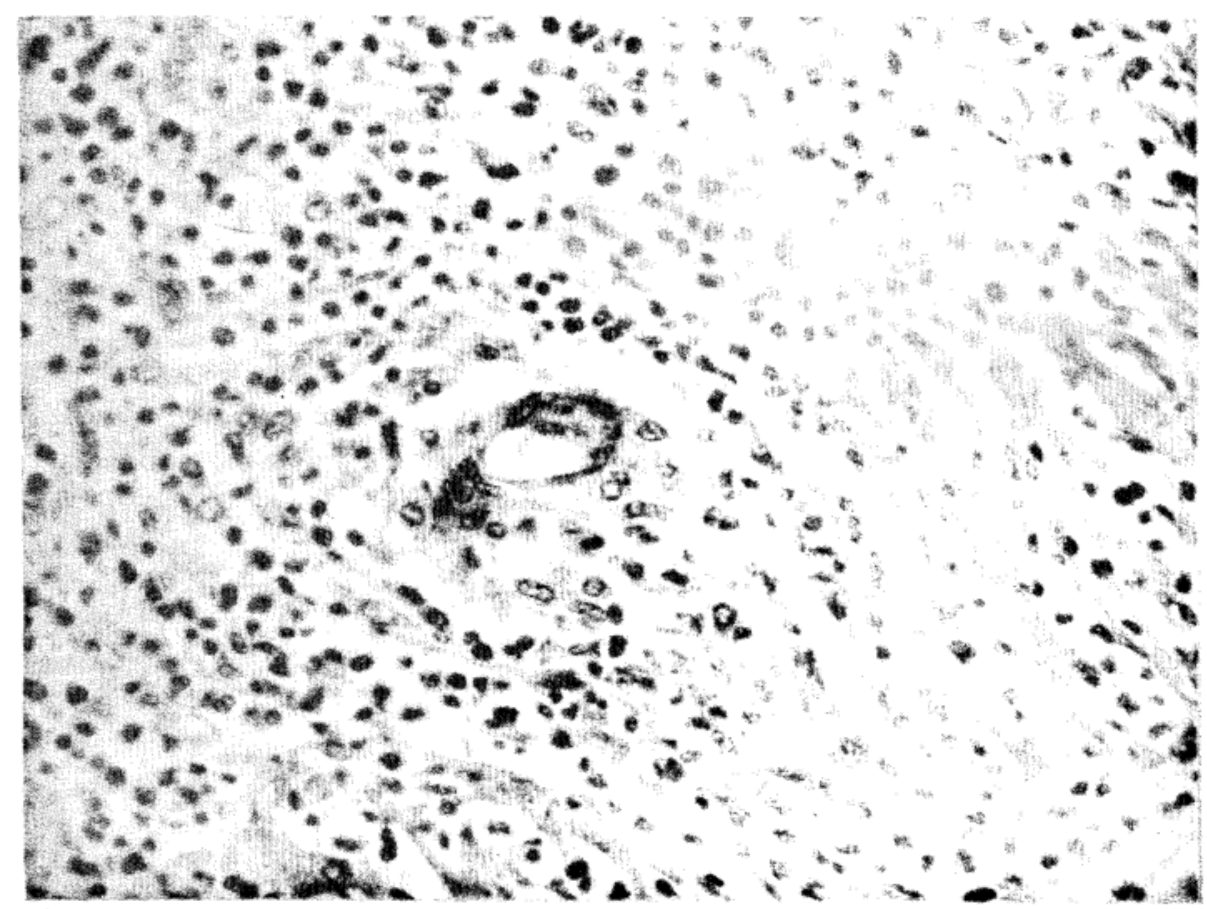

Figura 2 - Camada musuclar do ceco mostrando: ovo de parede delgada, associada a células gigantes de tipo corpo estranho e macrófagos; acentuada infiltraçâo leucocitária da parede, com abundantes granulócitos eosinófilos. $\mathrm{HE}-400 x$. 
Comunicação. Rocha A, Moscardini Sobrinho J, Salomão EC. Angiostrongiliase abdominal. Primeiro relato de caso autóctone de Minas Gerias. Revista da Sociedade Brasileira de Medicina Tropical 24:266-267, out-dez, 1991

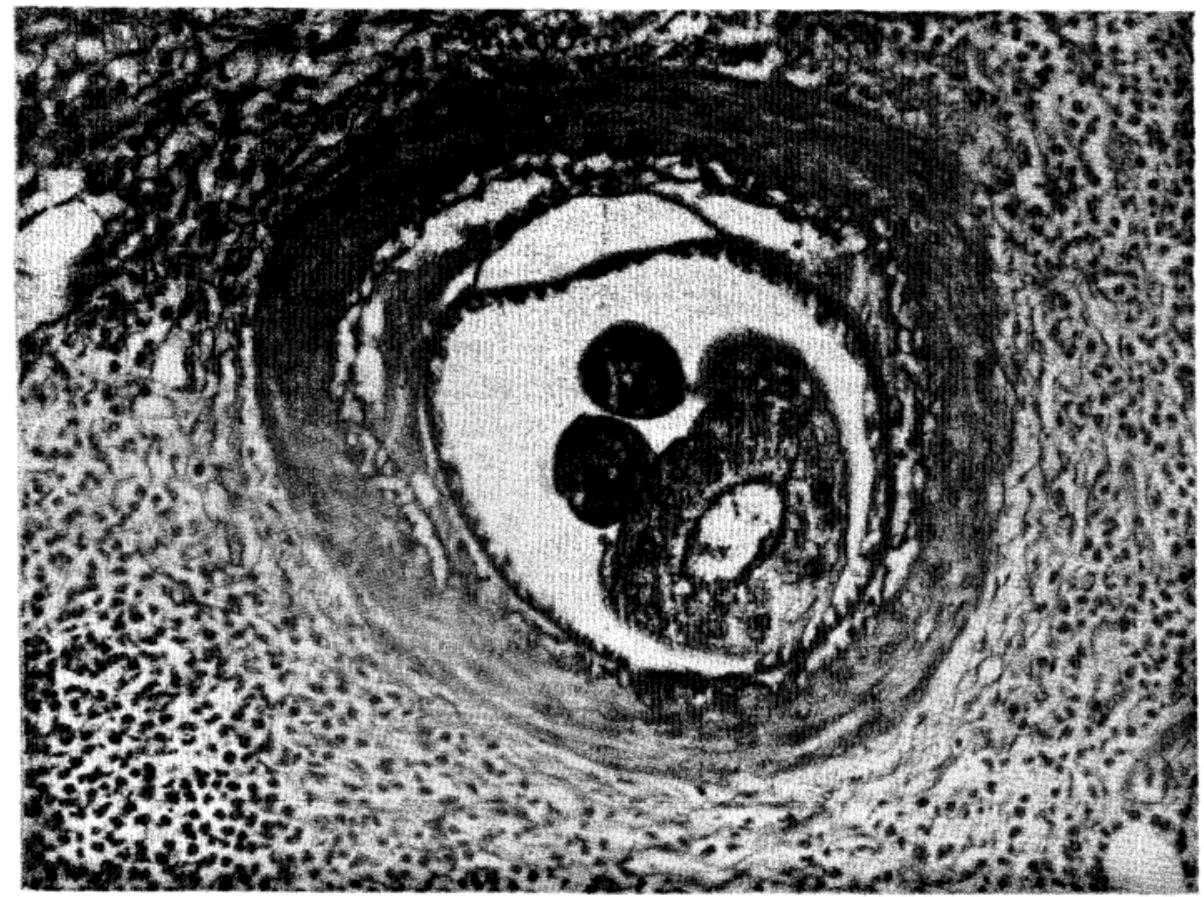

Figura 3 - Verme em cone transversal no lume de arteriola da submucosa. HE-200x.

O paciente recebeu alta hospitalar no quarto dia pós-operatório. Tem feito controles ambulatoriais periódicos, achando-se muito bem de saúde cerca de dois anos após a cirurgia.

Em face do diagnóstico anatomopatológico, indagamos à criança e seus pais, numa destas consultas, sobre condições de habitação, eventuais viagens etc. A família vive em bairro pobre da periferia de Uberlândia. Existem ratos no domicílio e na vizinhança, assim com lesmas nos quintais. $O$ paciente sempre morou em Uberlândia, com saídas esporádicas para férias em pequena cidade do interior de Goiás; a última viagem foi curta e ocorreu há cerca de três ou quatro meses. Diante do exposto, parece-nos muito provável que a doença tenha sido contraída na área da própria residência, caracterizando-se o primeiro caso mineiro de angiostrongilíase abdominal.

As alterações clínicas, laboratoriais e anatomopatológicas relatadas neste caso enquadram-se perfeitamente nos padrões previamente conhecidos de angiostrongilíase ${ }^{1410}$.
Deve-se ressaltar que, no homem, não ocorre a eliminação de ovos, larvas ou vermes adultos do $A$. costaricensis pelas fezes ${ }^{8}$. Um teste sorológico de precipitação do látex tem sido efetuado por Morera $^{6}$, na Costa Rica, para a deteç̧ão de anticorpos contra o parasita; não nos consta que este teste seja efetuado no Brasil. Assim, a definição do diagnóstico, em nosso país, exige a laparotomia exploradora e o exame anatomopatológico do segmento intestinal extirpado (ou de biópsias da parede intestinal). $\mathrm{O} A$. costaricensis representa o único helminto de localização essencialmente intraarterial descrito em nosso meio.

É possível que muitos casos caracterizados como inflamações eosinofílicas do tubo digestivo - e entre nós são relativamente frequentes as apendicites assim rotuladas - correspondam, na verdade à angiostrongilíase, hipótese já confirmada por Graeff-Teixeira e $\mathrm{col}^{3}$ na Região Sul. Faz-se mister o estudo meticuloso (se necessário, com múltiplos cortes histológicos, semi-seriados ou não) para avaliar tal possibilidade. 


\section{REFERÊNCIAS BIBLIOGRÁFICAS}

1. Agostini AA, Marcolan AM, Lisot JUF. Angiostrongilíase abdominal. Estudo anatomopatológico de quatro casos observados no Rio Grande do Sul, Brasil. Memórias do Instituto Oswaldo Cruz 79:443-445, 1984.

2. Barbosa H, Raick AN, Magalhães AV, Otero MF. Angiostrongilose abdominal. Revista da Associação Médica Brasileira 26:178-180, 1980.

3. Graeff-Teixeira C, Camilo-Coura L, Lenzi HL. Abdominal angiostrongyliasis - an underdiagnosed disease. Memórias do Instituto Oswaldo Cruz 82 (Suppl. IV):353-354, 1987.

4. Lobo Sanahuja F, Loría Cortés R, González G. Angiostrongilosis abdominal. Aspectos clínicos, tratamiento y revisión de la literatura. Boletin Médico del Hospital Infantil de México 44:4-9, 1987.

5. Magalhães AV, Andrade GE, Koh IHJ, Soares CM, Alves E, Tubino P, Santos FAM, Raick AN.
Novo caso de angiostrongilose abdominal. Revista do Instituto de Medicina Tropical de São Paulo 24:252-256, 1982.

6. Morera P. Abdominal angiostrongyliasis: a problem of public health. Parasitology Today 1:173-175, 1985.

7. Morera P. Angiostrongilíase abdominal. In: VeronesiR (ed) Doenças infecciosas e parasitárias, $8^{a}$ edição, Guanabara Koogan, Rio de Janeiro p.906-909, 1991.

8. Morera P, Céspedes R. Angiostrongilosis abdominal. Una nueva parasitosis humana. Acta Médica Costarricense 14:159-173, 1971.

9. Neves DP. Parasitologia humana, $7^{\mathrm{a}}$ edição, Atheneu, Rio de Janeiro p.457-458, 1988.

10. Rojas Ayala MA. Angiostrongiloidíase abdominal: seis casos observados no Paraná e em Santa Catarina, Brasil. Memórias do Instituto Oswaldo Cruz 82:26-29, 1987. 